\title{
A Comparison of Initial D-Dimers Concentration Determined in a Group of Patients With Coxarthrosis or Gonarthrosis and in a Group With Femoral Bone Fracture
}

\section{Lukasz Kacprzak ( luk-kac@wp.pl)}

Uniwersytet Medyczny w Lodzi https://orcid.org/0000-0003-3267-7473

\section{Piotr Bytniewski}

The State School of Professional Higher Education, Konin

\section{Research article}

Keywords: D-dimers, Total hip replacement, Total knee replacement, femoral fracture

Posted Date: January 23rd, 2020

DOl: https://doi.org/10.21203/rs.2.21683/v1

License: (c) (1) This work is licensed under a Creative Commons Attribution 4.0 International License. Read Full License 


\section{Abstract}

Introduction D-dimers are products of fibrin being degraded by thrombin, factor XIIla and plasmin. Their blood concentration is used in clinical diagnostics for venous thromboembolism (VTE) which involves deep vein thrombosis (DVT) and pulmonary embolism (PE). Purpose Surgical operations within the femoral bone are one of the most often performed ones in orthopedic wards. In order to determine an impact of bone injury on the risk of occurrence of a thromboembolic disease we compared the preoperative concentration of D-dimers between a group of patients hospitalized due to femur fracture and a group of patients hospitalized due to coxarthrosis or gonarthrosis.

Material and methods The study involved overall 404 patients, divided into two groups. The first group enrolled 283 patients who underwent elective surgery on the femoral bone: total hip replacement (THR) and total knee replacement (TKR) due to osteoarthritis of large joints. The second group enrolled 121 patients who underwent surgery due to femoral fracture. All patients underwent a physical examination for an occurrence of varicose veins in lower limbs. No clinical features of venous thromboembolism were found in patients qualified for the study, based on examination of the venous system in lower limbs, which was supplemented by ultrasound examination. Preoperative blood concentrations of D-dimers were measured in all participants.

Results In patients undergoing scheduled joint replacement surgery due to coxarthrosis or gonarthrosis Ddimers concentrations ranged between 122 and $7712 \mathrm{ng} / \mathrm{mL}$, with a mean of $822.3 \mathrm{ng} / \mathrm{mL}$ (SD 811.2 $\mathrm{ng} / \mathrm{mL}$ ). It was markedly lower than these found in patients with femur fracture: they ranged from 23.6 to $48340 \mathrm{ng} / \mathrm{mL}$, mean $8793.2 \mathrm{ng} / \mathrm{mL}(\mathrm{SD} \pm 10358.6 \mathrm{ng} / \mathrm{mL})$.

Conclusions It is suggested that elevated D-dimers levels observed in patients with femur fracture are not associated with an increased risk of occurrence of a thromboembolic disease.

\section{Introduction}

D-dimers were discovered in the 1970s, and their blood concentration was used in a clinical practice in the 1990s. They are a protein product of fibrin being degraded by thrombin, factor XIIla and plasmin. Determination of plasma D-dimers' concentration is used in diagnosis of venous thromboembolism (VTE), which includes deep vein thrombosis (DVT) and pulmonary embolism (PE). Low concentration of D-dimers allows to exclude the ongoing thromboembolic process, which indicates a large negative predictive value of this laboratory test. The commonly used cut-off value is a concentration below $500 \mathrm{ng} / \mathrm{mL}$, while higher concentrations indicate clinically significant VTE and such cases require indepth diagnostics. Although D-dimers are formed by degradation of fibrin, fibrin itself is not only associated with venous thromboembolism. Increased fibrin production, which is manifested by elevated D-dimers concentration, can also be seen in other clinical conditions such as cancer, infection, ongoing inflammation, surgery, injuries, hemorrhages, extensive burns, stroke, aortic aneurysm rupture, ischemia, heart disease, myocardial infarction, rheumatoid arthritis, pregnancy and the postpartum period, as well 
as in elderly patients, patients with hematomas, extensive bruising and many others [26]. Different methods used for measuring D-dimers concentration have a specificity of 93-95\%, while their sensitivity is only about $50 \%[1,2]$. Some authors suggest the correction of the D-dimers concentration determination for the patient's age using the cut-off age (in years) $x 5$ or $\times 10$. This allows increased specificity of the study among older patients. $[3,4,5]$.

Surgical operations within the femoral bone are one of the most often performed ones in orthopedic wards. In case of elective surgeries we deal with total hip replacement (THR) and total knee replacement (TKR). However, in case of fractures, it is necessary to use an appropriate prosthesis or osteosynthesis using a dynamic hip screw (DHS) or a proximal femoral nail (PFN). All these procedures are at risk of thromboembolic complications [6, 7]. In order to determine the impact of bone injury on this type of risk we compared the preoperative concentration of D-dimers between a group of patients hospitalized because of femoral fracture and a group of patients hospitalized due to coxarthrosis or gonarthrosis.

\section{Patients And Research Methods}

In this retrospective study we analyze medical records of patients who were operated on at the Orthopedics Department of SPZOZ in Turek (Poland) between August and November, 2011. Bioethics Committee of Medical University of Łódź allowed for data analysis; decision number: RNN/249/19/KE, issued: 14/05/2019.

Patients who were excluded from the analysis:

- patients with a diagnosed thromboembolic disorder or a disorder reported while taking a patient's medical history,

- patients with infections,

- patients with a recognized cancerous process,

- pregnant women,

- patients under 18 years old,

- incapacitated patients,

- patients taking oral anticoagulants.

Before qualifying for the study, data were obtained from the subjects by means of an interview and physical examination. The interview included past and accompanying chronic diseases, their current condition and undertaken therapy. The patients were examined in terms of the condition of the respiratory and circulatory systems and occurrence of varicose veins in lower limbs. No clinical features of venous thromboembolism were found in patients qualified for the research, based on examination of the venous system in lower limbs, which was supplemented by ultrasound examination.

Medical records of two groups of patients were analyzed. The first group enrolled 283 patients 
hospitalized due to osteoarthritis of the hip or knee, including 186 women and 97 men at the age between 29 and 87; the average age was 65.59. The second group enrolled 121 patients hospitalized for a femoral fracture, including 97 women and 24 men, aged between 48 and 99; the average age was 77.38. Body mass index (BMI) was calculated for all patients. Characteristics of both groups of patients in terms of age, sex and BMI are presented in Table 1. An operational risk associated with the occurrence of serious complications or death during or after anesthesia was determined according to the American Society of Anesthesiologists physical status classification system. [8]. The study included only preoperative determination of D-dimers concentration as the surgery itself could increase their levels [9]. Concentration of D-dimers in blood plasma was measured by an enzyme immunoassay test VIDAS D-Dimer Exclusion, conducted in VIDAS immunology analyzer (BioMérieux, Marcy-l'Étoile, France) and based on marking fibrin degradation products (FbDP), using an enzyme-linked fluorescent assay (ELFA).

Data collected from both groups were analyzed using Statistica 10 (Statsoft Dell, Tusla, OK, USA). P $<0.05$ was considered statistically significant.

\section{Results}

Among 283 patients with osteoarthritis of the hip or knee, D-dimers levels ranged between 122 and 7712 $\mathrm{ng} / \mathrm{mL}$, with the mean of $822.34 \mathrm{ng} / \mathrm{mL}$ (SD $\pm 891.2 \mathrm{ng} / \mathrm{mL}$ ). The mean preoperative D-dimers concentration for women in this group was $896.9 \mathrm{ng} / \mathrm{mL} \pm 988.0$, while in men $679.4 \mathrm{ng} / \mathrm{mL} \pm$.648.6. The average BMl in this study group was $29.22 \pm 4.7 \mathrm{~kg} / \mathrm{m} 2$ (Table 2 ).

In 212 out of $283(74.91 \%)$ patients hospitalized for osteoarthritis of the hip or knee blood D-dimers levels were below $<1000 \mathrm{ng} / \mathrm{mL}$. D-dimers concentrations in women were not statistically different from those in men $(p=0.05)$.

Analysis of data did not show statistically meaningful correlations between BMI or ASA qualification of patients and preoperative D-dimers concentration.

Among 121 patients with femur fracture D-dimers levels ranged between 23.55 and $48340 \mathrm{ng} / \mathrm{mL}$, with a mean of $8793.2 \mathrm{ng} / \mathrm{mL}$ (SD $10358.6 \mathrm{ng} / \mathrm{mL}$ ). The mean of preoperative D-dimers level for women in this group was $8463.2 \pm 9653.2 \mathrm{ng} / \mathrm{mL}$, while in men $10126.6 \mathrm{ng} / \mathrm{ml} \pm 12983.5 \mathrm{ng} / \mathrm{ml}$. The data have been shown in Table 3.

In a group of 93 patients the concentration of D-dimers was $<10000 \mathrm{ng} / \mathrm{ml}$ which is as much as $76.859 \%$ of the group hospitalized due to femur fracture.

The mean concentration of D-dimers in women from the group hospitalized due to femoral fracture was nearly 10 times higher than that in women from the group hospitalized due to coxarthrosis or gonarthrosis. In case of men who were hospitalized due to femur fracture, the mean blood level of Ddimers was about 15 times higher than that in men from the group hospitalized due to coxarthrosis or gonarthrosis. 
The mean BMI for the group of patients with a femur fracture was $25.29 \pm 4.6 \mathrm{~kg} / \mathrm{m}^{2}$ (Table 3). No significant differences between men and women were observed. The obtained data do not indicate any meaningful correlations between the analyzed parameters.

\section{Discussion}

Preoperative blood level of D-dimers presented in the present study shows how much fracture may increase this parameter compared to a chronic degenerative process. Similar results were obtained by Hagiwara et al. who showed correlations between the concentration of D-dimers at the time of admission to the hospital and the severity of an injury according to Injury Severity Score [10]. Yu-Jun Zhu et al. demonstrated elevated concentrations of D-dimers in various types of injuries, regardless of the part of the body [11], it is difficult to determine whether differences between men and women observed by us result from gender or general health condition of patients in the studied population.

In the previous research conducted by Bytniewski et al. on a group of 47 patients at the age of 29-82, who were treated for coxarthrosis and underwent total hip replacement (THR) using both cemented and uncemented prostheses, the initial preoperative $D$-dimers concentrations exceeded the reference value of $500 \mathrm{ng} / \mathrm{mL}$ in 37 out of 47 patients, with a mean value ranging from 1077.2 to $2075.5 \mathrm{ng} / \mathrm{mL}$, depending on the age group [26]. Thus, the cited data indicate that an increase in D-dimers concentration after surgery is not associated with a higher risk of thromboembolic disease. In line with this, Waśko et al. demonstrated that concentration of D-dimers before scheduled hip joint replacement surgery is above the limit $(500 \mathrm{ng} / \mathrm{mL})$, but does not correlate with the risk of thromboembolic events. Thus, D-dimers should be considered acute phase proteins [12].

Degenerative disease may be considered a factor of hypercoagulability leading to an increase of laboratory parameters, including blood D-dimers levels [13, 14]. According to Mameli and Marongiu, patients with rheumatoid arthritis who demand orthopedic intervention, are at a similar risk of thromboembolic complications like general population taking appropriate prophylaxis into account [15]. In turn, Mukubo and Kawamata argue that patients suffering from rheumatoid arthritis have higher preoperative concentrations of D-dimers than patients operated due to hip joint osteoarthritis [25]. The issue undoubtedly requires further research. One should bear in mind the necessity of correction of the cut-off point, taking into account patients' age (age in years x $10 \mathrm{ng} /$ over 50 years old), which can be observed in the group of patients operated due to osteoarthritis of the hip or knee [16-18].

Liu et al. point out the difference in the magnitude of increased concentrations of D-dimers which were dependent on a fracture's location; the highest changes are observed in case of fractures localized close to the femoral bone (mean concentration of D-dimers: $2448 \pm 1961 \mathrm{ng} / \mathrm{mL}$ ) [19]. Differences may result from the diversity of the population or the size of the studied subjects. Other authors also indicate the impact of femoral fracture on functioning of the coagulation system. Therefore, not surprisingly, it is difficult to interpret D-dimers levels in patients suffering from trauma [20-21]. 
While examining patients hospitalized for femur fracture prior to the surgery Luksameearunothai et al. did not observe significant differences in D-dimers levels between patients who developed deep vein thrombosis (DVT) and the remaining ones. All injured patients had significantly elevated concentrations of D-dimers [22]. It should also be borne in mind that older patients may suffer from previously recognized thromboembolic disorders. Therefore, when clinical symptoms occur, other diagnostic tools, such as Doppler ultrasonography and computed tomography with the administration of a contrast agent should be used [23]. In our study, ultrasound diagnostics excluded the ongoing thromboembolic process in both examined groups, despite the increased concentrations of D-dimers.

Niikura et al. claim that in the group of patients who incurred a high-energy fracture, the concentration of D-dimers is of significant importance in the diagnosis of thromboembolic complications.

Our study has numerous limitations. First of all, this is a retrospective analysis conducted in one medical center only. Despite a significant number of patients included in the research, it would be vital to perform a multi-center research.

\section{Conclusions}

1. The mean concentration of D-dimers in the group with femur fracture was higher than in the group with coxarthrosis or gonarthrosis.

2. The increase in D-dimer concentration in the group of patients with femoral fracture was not associated with an increased risk of thromboembolic disease.

\section{Abbreviations Used}

VTE - venous thromboembolismDVT - deep vein thrombosisPE - pulmonary embolismTHR - total hip replacementTKR - total knee replacementDHS - dynamic hip screwPFN - proximal femoral nailBMI body mass indexASA - American Society of Anesthesiologists

\section{Declarations}

Availability of data and materials:

All data were acquired at the Department of Orthopedics and Traumatology, Health Maintenance Organization in Turek, 1 Poduchowne Street, 62-700 Turek, Poland.

The data that support the findings of this study are available from Health Maintenance Organization in Turek but restrictions apply to the availability of these data which were used under permission of the director of medical affairs of Health Maintenance Organization in Turek for the current study, and therefore are not publicly available. However, the data are available to obtain from the authors upon reasonable request and with permission of Health Maintenance Organization in Turek. 
Ethics approval and consent to participate:

Protocol of this study was ethically approved by Bioethics Committee of Medical University of Łódź and given a certificate number: RNN/249/19/KE, issued: 14/05/2019. Only consented participants were enrolled in this study, over 18 years old with full legal capacity.

Competing interests:

The authors declare that they have no competing interests.

\section{Funding:}

The authors received no financial support for the research, authorship, and/or publication of this article.

Consent for publication:

None applicable.

\section{Authors' contributions}

$\measuredangle K$ and PB conceived of the study, participated in its design and coordination and helped to draft the manuscript. $Ł K$ and PB carried out the design of the study and the statistical analysis. $Ł K$ carried out the editing of the text and tables and prepared the edition of this manuscript for publication. $Ł K$ was responsible for the translation into English and editing the text. Both authors read and approved the final manuscript.

\section{Authors' information}

Łukasz Kacprzak is the first author and a corresponding author. MD; a PhD student at the Department of Pharmacodynamics, Medical University of Lodz, Poland.

Piotr Bytniewski is a co-author, MD, PhD , head of Anesthesiology Department, Health Maintenance Organization in Turek, Poland; faculty of Physical Education and Health Preservation, The State School of Professional Higher Education in Konin, Poland.

\section{Contact Information}

Łukasz Kacprzak, email: luk-kac@wp.pl

Piotr Bytniewski, email: piotrbyt@pocztaonet.pl

\section{References}

[1] Adam SS, Key NS, Greenberg CS. D-dimer antigen: current concepts and future prospects. Blood 2009; 113 (13): 2878-2887. doi:10.1182/blood-2008-06-165845 
[2] Schrecengost JE, Le Gallo RD, Boyd JC, Moons KG, Gonias SL, Rose CE, Bruns DE. Comparison of diagnostic accuracies in outpatients and hospitalized patients of D-dimer testing for the evaluation of suspected pulmonary embolism. Clin Chem 2003; 49 (9): 1483-1490. doi:10.1373/49.9.1483.

[3] Dutton J, Dachsel M, Crane R. Can the use of an age adjusted D-dimer cut-off value help in our diagnosis of suspected pulmonary embolism? Clin Med 2018; 18:293-296.

[4] Douma RA. Le Gal G, Söhne M, et al. Potential of an age adjusted D-dimer cut-off value to improve the exclusion of pulmonary embolism in older patients: a retrospective analysis of three large cohorts. BMJ 2010; 340: c1475.

[5] Haas FJ. Schutgens RE, Biesma DH. An age-adapted approach for the use of D-dimers in the exclusion of deep venous thrombosis. Am J Hematol 2009; 84: 488-491.

[6] Blanié A, Bellamy L, Rhayem Y, et al. Duration of postoperative fibrinolysis after total hip or knee replacement: a laboratory follow-up study. Thromb Res 2013; 131: e6.

[7] Nalewajka M, Gaździk TSZ. 3 (11) 2008DVT risk factors after total hip or knee replacement. J Orthop Trauma Surg Rel Res 2008; 10: 25-34.

[8] Nicholas J. Hackett, Gildasio S. De Oliveira, Umang K. Jain, John Y.S. Kim, ASA class is a reliable independent predictor of medical complications and mortality following surgery, Int J Surg 2015; 18: 184190. doi.org/10.1016/j.ijsu.2015.04.079

[9] Jiang, Y., Li, J., Liu, Y., \& Zhang, W. (2016). Diagnostic accuracy of deep vein thrombosis is increased by analysis using combined optimal cut-off values of postoperative plasma D-dimer levels. Exp Ther Med 2016; 11: 1716-1720. doi.org/10.3892/etm.2016.3125

[10] Hagiwara S, Oshima K, Aoki M, et al. Usefulness of fibrin degradation products and d-dimer levels as biomarkers that reflect the severity of trauma. J Trauma Acute Care Surg. 2013; 74 (5): 1275-1278.

[11] Yu-jun ZHU, Xian-kai HUANG,Relationship between disseminated intravascular coagulation and levels of plasma thrombinogen segment 1+2, D-dimer, and thrombomodulin in patients with multiple injuries,Chinese Journal of Traumatology (English Edition),Volume 12, Issue 4,2009,Pages 203-209,ISSN 1008-1275,

https://doi.org/10.3760/cma.j.issn.1008-1275.2009.04.003.

[12] Wasko, Marcin K.; Burbul, Marta; Gawronski, Krzysztof; Peplonski, Artur; Kwiatkowski, Krzysztof (2018): D-dimer Levels are not a Good Marker for Venous Thromboembolism in Patients Before and After Total Hip Replacement. w: Ortopedia, traumatologia, rehabilitacja 20 (5), s. 401-408. DOI: 10.5604/01.3001.0012.8276. 
[13] Iturbe T, Cornudella R, de Miguel R, Olave T, Moreno J, Gutiérrez M. Existence of a hypercoagulability state prior to pro -sthetic hip or knee surgery. Haematologica 1999; 84: 87.

[14] Wanderling C, Liles J, Finkler E, et al. Dysregulation of Tissue Factor, Thrombin-Activatable Fibrinolysis Inhibitor, and Fi -brinogen in Patients Undergoing Total Joint Arthroplasty. Clin Appl Thromb Hemost 2017; 23: 967.

[15] Mameli A, Marongiu F. Thromboembolic disease in patients with rheumatoid arthritis undergoing joint arthroplasty: Update on prophylaxes. World J Orthop. 2014;5(5):645-652. Published 2014 Nov 18. doi:10.5312/wjo.v5.i5.645

[16] HAGER K, PLATT D. Fibrin degeneration product concentrations (D-dimers) in the course of ageing. Gerontology (Basel). 1995;(3):159. http://search.ebscohost.com/login.aspx? direct=true\&db=edscal\&AN=edscal.3462343\&lang=pl\&site=eds-live\&scope=site. Accessed June 5, 2019.

[17] Lim, M. S., Bennett, A. and Chunilal, S. (2018), Age-adjusted cut-off using the IL D-dimer HS assay to exclude pulmonary embolism in patients presenting to emergency. Intern Med J, 48: 1096-1101. doi:10.1111/imj.13992

[18] Douma, Renee A.; Le Gal, Gregoire; Sohne, Maaike; Righini, Marc; Kamphuisen, Pieter W.; Perrier, Arnaud i wsp. (2010): Potential of an age adjusted D-dimer cut-off value to improve the exclusion of pulmonary embolism in older patients: a retrospective analysis of three large cohorts. w: BMJ (Clinical research ed.) 340, c1475. DOI: 10.1136/bmj.c1475.

[19] Liu C, Song Y, Zhao J, et al. Elevated D-dimer and fibrinogen levels in serum of preoperative bone fracture patients. Springerplus. 2016;5:161. Published 2016 Feb 24. doi:10.1186/s40064-016-1817-1

[20] Okamura K, Nakagawa I, Hidaka S, Okada Y, Kubo T, Kato T. Perioperative changes of the coagulation markers in patients undergoing hip fracture surgery. Masui Jpn J Anesthesiol. 2007;56(11):1353-1357.

[21] Huang W, Xu LY, Shao SY, Yao L, Wang TB. Impact of hip fracture on coagulation function in elderly patients. Beijing Da Xue Xue Bao. Yi Xue Ban = Journal of Peking University. Health Sciences. 2013;45(5):742-744. [PubMed] [Google Scholar]

[22] Luksameearunothai K, Sa-Ngasoongsong P, Kulachote N, et al. Usefulness of clinical predictors for preoperative screening of deep vein thrombosis in hip fractures. BMC Musculoskelet Disord. 2017;18(1):208. Published 2017 May 22. doi:10.1186/s12891-017-1582-5

[23] Xing F, Li L, Long Y, Xiang Z. Admission prevalence of deep vein thrombosis in elderly Chinese patients with hip fracture and a new predictor based on risk factors for thrombosis screening. BMC Musculoskelet Disord. 2018;19(1):444. Published 2018 Dec 20. doi:10.1186/s12891-018-2371-5

[24] Niikura, Takahiro; Sakai, Yoshitada; Lee, Sang Yang; Iwakura, Takashi; Nishida, Kotaro; Kuroda, Ryosuke; Kurosaka, Masahiro (2015): D-dimer levels to screen for venous thromboembolism in patients 
with fractures caused by high-energy injuries. w: Journal of orthopaedic science : official journal of the Japanese Orthopaedic Association 20 (4), s. 682-688. DOI: 10.1007/s00776-015-0711-y.

[25] Mukubo, Y. \& Kawamata, M. J Anesth (2006) 20: 51. https://doi.org/10.1007/s00540-005-0368-3

[26] Bytniewski, P., Machała, W., Romanowski, L., Wiśniewski, W., \& Kosowski, K. (2014). The dynamics of D-dimer level fluctuation in patients after the cemented and cementless total hip and total knee replacement. Journal of orthopaedic surgery and research, 9, 89. doi:10.1186/s13018-014-0089-0

\section{Tables}

Table 1. Characteristics of the study groups.

\begin{tabular}{|c|c|c|}
\hline & \multicolumn{2}{|c|}{ Reason for hospitalization } \\
\hline & $\begin{array}{c}\text { Coxarthrosis or gonarthrosis } \\
\qquad(\mathrm{n}=283)\end{array}$ & $\begin{array}{c}\text { Femur fracture } \\
(\mathrm{n}=121)\end{array}$ \\
\hline Age (mean \pm SD) & $65.60 \pm 9.88$ & $77.38 \pm 12.43$ \\
\hline Age (min) & 29 & 48 \\
\hline Age (max) & 87 & 99 \\
\hline $\mathrm{BMI}($ mean $\pm \mathrm{SD})$ & $29.22 \pm 4.70$ & $25.30 \pm 4.60$ \\
\hline BMI (min) & 16.91 & 16.49 \\
\hline $\mathrm{BMI}(\max )$ & 44.44 & 41.52 \\
\hline Woman & $\mathrm{n}=186$ & $\mathrm{n}=97$ \\
\hline Age (mean \pm SD) & $66.29 \pm 10.39$ & $79.31 \pm 11.24$ \\
\hline $\mathrm{BMI}($ mean $\pm \mathrm{SD})$ & $29.27 \pm 4.8$ & $21.13 \pm 4,81$ \\
\hline Men & $\mathrm{n}=97$ & $\mathrm{n}=24$ \\
\hline Age (mean \pm SD) & $64.27 \pm 8.70$ & $69.60 \pm 14.14$ \\
\hline BMI (mean \pm SD) & $29.11 \pm 4.37$ & $25.97 \pm 3.60$ \\
\hline
\end{tabular}

Table 2. ASA scores, BMI and preoperative blood D-dimer concentrations in the group of patients hospitalized due to osteoarthritis of the hip or knee 


\begin{tabular}{|c|c|c|c|c|c|}
\hline Gender & $\begin{array}{c}\text { ASA } \\
\text { scores }\end{array}$ & $\begin{array}{c}\text { Number of } \\
\text { patients }\end{array}$ & $\begin{array}{c}\text { Age (years; } \\
\text { mean } \pm \text { SD) }\end{array}$ & $\begin{array}{c}\text { BMI }\left(\mathrm{kg} / \mathrm{m}^{2},\right. \\
\text { mean } \pm \text { SD) }\end{array}$ & $\begin{array}{c}\text { Preoperative D-dimer } \\
\text { concentration } \\
(\mathrm{ng} / \mathrm{mL}, \mathrm{mean} \pm \text { SD) }\end{array}$ \\
\hline $\begin{array}{c}\text { Women } \\
\text { overall }\end{array}$ & - & 186 & $66.29 \pm 10.39$ & $29.27 \pm 4.87$ & $896,9 \pm 988.0$ \\
\hline \multirow{3}{*}{ Women } & 1 & 11 & $42.27 \pm 7.78$ & $25.14 \pm 3.35$ & $264.3 \pm 126.5$ \\
\cline { 2 - 6 } & 2 & 55 & $62.20 \pm 7.08$ & $28.58 \pm 4.37$ & $708.4 \pm 654.7$ \\
\cline { 2 - 6 } & 3 & 107 & $69.77 \pm 7.82$ & $30.34 \pm 4.87$ & $1083.46 \pm 1167.23$ \\
\cline { 2 - 6 } & 4 & 13 & $75.31 \pm 6.96$ & $26 ., 90 \pm 5.24$ & $694.4 \pm 431.8$ \\
\hline $\begin{array}{c}\text { Men } \\
\text { overall }\end{array}$ & - & 97 & $64.27 \pm 8.70$ & $29.11 \pm 4.37$ & $679.4 \pm 648.6$ \\
\hline \multirow{2}{*}{ Men } & 1 & 8 & $52.62 \pm 5.10$ & $29.60 \pm 5.23$ & $654.8 \pm 715.8$ \\
\cline { 2 - 6 } & 2 & 32 & $61.16 \pm 8.95$ & $28.33 \pm 4.26$ & $468.5 \pm 241.3$ \\
\cline { 2 - 6 } & 3 & 44 & $66.57 \pm 7.04$ & $29.27 \pm 4 ., 44$ & $724.8 \pm 697.6$ \\
\cline { 2 - 6 } & 4 & 13 & $71.31 \pm 4.17$ & $30.19 \pm 4.03$ & $1060.1 \pm 942.8$ \\
\hline $\begin{array}{c}\text { Group } \\
\text { overall }\end{array}$ & - & 283 & $65.60 \pm 9.88$ & $29.22 \pm 4.70$ & $8224.0 \pm 891.2$ \\
\hline
\end{tabular}

Table 3. ASA scores, BMI and preoperative blood D-dimer concentrations in the group of patients hospitalized due to the femoral fracture

\begin{tabular}{|c|c|c|c|c|c|}
\hline Gender & $\begin{array}{c}\text { ASA } \\
\text { scores }\end{array}$ & $\begin{array}{c}\text { Number of } \\
\text { patients }\end{array}$ & $\begin{array}{c}\text { Age (years; } \\
\text { mean } \pm \text { SD) }\end{array}$ & $\begin{array}{c}\text { BMI }\left(\mathrm{kg} / \mathrm{m}^{2} ;\right. \\
\text { mean } \pm \text { SD) }\end{array}$ & $\begin{array}{c}\text { Preoperative D-dimer } \\
\text { concentration } \\
(\mathrm{ng} / \mathrm{mL} \text { mean } \pm \text { SD) }\end{array}$ \\
\hline $\begin{array}{c}\text { Women } \\
\text { overall }\end{array}$ & - & 97 & $79.31 \pm 11.24$ & $21.13 \pm 4.81$ & $8463.2 \pm 9653.2$ \\
\hline Women & 1 & - & - & - & - \\
\cline { 2 - 6 } & 2 & 9 & $61.78 \pm 7,39$ & $26.18 \pm 2.85$ & $6033.8 \pm 4025.0$ \\
\cline { 2 - 6 } & 3 & 17 & $72.12 \pm 10.41$ & $25.94 \pm 4.60$ & $6435.9 \pm 11360.7$ \\
\cline { 2 - 6 } & 4 & 71 & $83.25 \pm 8.63$ & $24.80 \pm 5.06$ & $9256.6 \pm 9697.8$ \\
\hline \multirow{2}{*}{$\begin{array}{c}\text { Men } \\
\text { overall }\end{array}$} & - & 24 & $69.60 \pm 14.14$ & $25.97 \pm 3.60$ & $10126.6 \pm 12983.5$ \\
\hline \multirow{2}{*}{ Men } & 1 & - & - & - & - \\
\cline { 2 - 6 } & 2 & 3 & $57.67 \pm 7.23$ & $24.60 \pm 2.06$ & $16268.7 \pm 2545.8$ \\
\cline { 2 - 6 } & 3 & 5 & $62.60 \pm 9.91$ & $23.73 \pm 0.88$ & $9473.0 \pm 10515.2$ \\
\cline { 2 - 6 } & 4 & 16 & $74.00 \pm 14.43$ & $26.93 \pm 4.01$ & $9179.2 \pm 11692.2$ \\
\hline \multirow{2}{*}{$\begin{array}{c}\text { Group } \\
\text { overall }\end{array}$} & - & 121 & $77.38 \pm 12.43$ & $25.30 \pm 4.60$ & $8793.2 \pm 10358.6$ \\
\hline
\end{tabular}


Page 12/12 